Article

\title{
Neutralisation and Mental Accounting in Ethical Consumption: The Case of Sustainable Holidays
}

\section{Larissa Schütte ${ }^{1}$ and Diana Gregory-Smith ${ }^{2, *}$}

1 Durham University Business School, Queen's Campus, University Boulevard, Thornaby, Stockton-on-Tees TS17 6BH, UK; E-Mail: schuette.uk@googlemail.com

2 Sheffield University Management School, University of Sheffield, Conduit Road, Sheffield S10 1FL, UK

* Author to whom correspondence should be addressed; E-Mail: d.gregory-smith@ sheffield.ac.uk; Tel.: +44-0-114-222-3264.

Academic Editor: Marc A. Rosen

Received: 15 March 2015 / Accepted: 15 June 2015 / Published: 19 June 2015

\begin{abstract}
The present research aimed to investigate the decision-making process for sustainable holidays, as a type of ethical consumption related to environmental welfare. Using semi-structured in-depth interviews with 20 German holidaymakers of different ages, it was found that individuals use cognitive processes such as neutralisation and mental accounting to justify their unethical/unsustainable choices and to manage negative emotions. The findings also indicated a lack of spillovers between sustainable behaviours at home and holiday-related behaviours. This could be explained by the identification of "ethical" and "unethical" mental accounts, which the interviewees have disclosed. When the compensation between the two types of mental accounts takes place, neutralisation is not used. It was also found that positive and negative emotions could motivate the choice of sustainable holidays. These findings have implications in relation to marketing communications aimed at creating awareness and encouraging the purchase of sustainable holidays.
\end{abstract}

Keywords: sustainable holidays; ethical consumption; neutralisation; mental accounting; emotions 


\section{Introduction}

Recent empirical research suggests there are an increasing number of ethically minded consumers. Yet, a broader shift in consumption behaviour is mitigated by the attitude-behaviour gap or due to inconsistency in behaviours [1-5]. These tendencies can be noticed in various areas of sustainable consumption, including holiday decision-making. Here, individuals often claim to be environmentally responsible, but disregard ecological values when booking their holidays or travelling [6-8]. Although there is a significant body of literature about ethical consumption in relation to fair trade [9], organic [10] and unethical labour practices in production [11], the research on sustainable tourism products is much more limited. A small number of studies have looked at cognitive decisional processes sustainable tourism holidays, but none appears to have focused on neutralisation and mental accounting or on how sustainable tourism choices and behaviours are connected to/disconnected from other areas of ethical consumption. This study aims to fill these research gaps.

The term ethical consumption relates to the purchase of organic, local and fair trade products, the boycott of unethical organisations [12] as well as purchasing products that are low in carbon emissions, among others [13]. Ethically orientated consumers are considered to display their concerns in at least one of the subsequent areas: human welfare, animal welfare or environmental welfare [14]. In relation to this classification, sustainable holidays could be largely classified as a type of tourism products that are related to concerns about "environmental welfare" [14].

Despite rising interest in ethical products there is an obvious "ethical purchasing gap" [15] akin to the "attitude-behaviour gap" [16] since, even among self-declared ethical consumers, intentions do not often translate into actual behaviour [17]. This conduct emerges despite consumers' sense of "ethical obligation" and "self-identity", which sometimes drives ethical decision-making [18]. In the light of these findings, more research is needed about the underlying decisional mechanisms that lead to the purchase of ethical, versus the mainstream product [19]. In particular, the area of sustainable tourism/holidays has been less researched, probably due to the complexity of tourism products and the related decision-making process [20] compared to regular food or clothing products.

Some recent research draws attention to the need to consider the ethical and moral dimension [21-23], and particularly environmental ethics in the context of tourism [24]. Over the past decade there has been an increase in the attention paid by certain holidaymakers to the external effects of their travel activities and behaviour [25]. While some research has focused on the ethics and human rights associated with travel decisions [26], more recent research points out the contribution of tourism to increasing $\mathrm{CO}_{2}$ emissions [27,28], with predictions for 2035 estimating an increase of approximately $135 \%$, compared to 2005 figure [29].

Travelling is a big component of holidays and, thus, a large number of studies researching holidaymakers' behaviour have focused mainly on the modes of transport and travelling choices [30,31]. Given the lack of clear definition of sustainable holidays, in the present paper we define sustainable holidays as a complex and multi-faced product that includes a range of activities and sustainability aspects including the destination, accommodation, travelling group, duration, etc. [32]. A large amount of research into sustainable tourism/holidays has focused mainly on the sustainability dimension of travelling, as this can be recalled easily by holidaymakers and measured in terms of negative outcomes (i.e., emissions). Other resources that might be used in the provision of certain aspects of the holiday 
(such as energy, food, water, human labour) are not always visible for holidaymakers. Therefore, it is difficult for individuals to exactly quantify or identify a certain threshold that would separate sustainable from unsustainable holidays. This is similar to the operational, managerial and academic view on setting certain standards for measuring the triple bottom line of sustainability in tourism [33].

Although a larger number of tourists claim to be environmentally orientated in terms of their holiday choices, the number of tourists who actually purchase ethical and sustainable tourism products or select a more environmentally friendly means of transport is still low [34]. This can be explained by the lack of translation of environmental values and attitudes into actual behaviour when booking a holiday [6].

Some researchers argue that the green values might not be translated to tourism-related travelling behaviour [35,36]. Hall [37] (p. 1094) proposes personal and individual factors as an explanation as "sustainable tourism consumption information is individually and socially contextualised and actioned". However, a more detailed and focused explanation is needed, particularly in relation to the underlying decisional mechanisms.

Some research into individual sustainable behaviour has highlighted the spillover phenomenon between different types of home or daily behaviours (e.g., energy saving, purchasing, habitual [38,39]). Some studies have proposed mixed findings regarding the spillovers between sustainable practices [40]. Thørgersen [41] considers that consumers should have a desire to behave consistently in the case of similar environmental behaviours, but this will not be the case where different environmental behaviours are substitutes. However, others such as Haq et al. [42] note the difficulty of assuming the spillover between different practices and contexts. This has been confirmed by Barr, Shaw and Gilg [36] who noted a lack of spillover between sustainable home behaviours and tourism-related behaviour such as travelling. Nevertheless, a comprehensive explanation for this phenomenon is lacking. Thus, despite the extant research in the area of environmental spillovers, our study will contribute to this stream of research by examining the decision-making for holidays, which are hedonic, complex products (as per our explanations and proposed definition above) and purchased infrequently.

Other research into holidaymaking and travelling choices has provided a segmentation of individuals based on attitudes, mode of transport choice and perceived environmental benefits [30,43] but they do not shed much light on the reasons for behavioural discrepancies or the attitude-behaviour gap.

An interesting market to examine in relation to sustainable holidays is represented by German holidaymakers. Past research has described these individuals as being largely ethical, i.e., highly aware of ecological issues, concerned by animal welfare, considering organic products among their daily purchases, and with environmental values and behaviour being displayed more saliently among the younger generation (i.e., 25-34 years old) than among older consumers [44]. In relation to tourism, previous research considers Germans to be more environmentally minded tourists as compared to their European counterparts, such as British and French tourists. This was attributed to their special interest in authentic, nature-based holiday choices [45]. However, other studies have found out that German tourists show inconsistent behaviour, as "constraints concerning holiday travel are obviously less acceptable than constraints in everyday life" [6]. Convenience, flexibility, comfort, availability and time are overriding factors in the choice of travel mode [46], which are likely to be prioritised over sustainability characteristics. Given these complex findings and the apparent inconsistent ethical behaviour among German consumers, a deeper understanding of the decisional mechanisms among these types of consumers would contribute to the extant literature and also marketing practices. 
One of the theories used to explain generic unethical behaviour is the neutralisation theory. According to this theory, consumers use various rationalisation techniques to overcome the cognitive dissonance aroused by behaviour contradictory to their claimed ethical orientation [47,48]. Chatzidakis et al. [49] and McGregor [50] highlighted numerous neutralisation techniques that are used by consumers to justify their unethical consumption such as denial of responsibility, denial of injury, denial of victim, condemning the condemners and appealing to higher loyalties. Alternatively, D'Astous and Legendre [47] have identified three main neutralisation techniques: economic rationalisation, economic development reality, and government dependency. However, no studies have examined neutralisation strategies in the context of sustainable tourism, in particular holidays. This is a gap that this research addresses.

The theory of rational choice postulates that consumption choices demonstrate certain levels of consistency and coherence. However, consumers often behave in ways that are inconsistent and incoherent to what they intend to do [4,51]. This is particularly obvious in the context of ethical consumption as exemplified by the attitude-behaviour gap [1].

Given this incongruity between the theory and context, it would be useful to examine if and how consumers (who display some degree of ethical concern) might use mental accounting in decisions related sustainable holidays as a form of ethical tourism. The theory of mental accounting [52] suggests that consumers possess mental accounts for diverse types of consumption choices and expenditures. According to Thaler [52], consumers tend to label expenses and their purchases and afterwards group them into accounts such as regular income versus windfall gains, as well as utilitarian (e.g., paying electricity bills) versus hedonic (e.g., luxury products) consumption. The concept of mental accounting also embodies an aspect of frequency (e.g., daily, weekly, yearly) with which mental accounts being evaluated by the consumer [52]. Consumers are believed to have specific preferences for matching certain mental accounts. Thus, certain expenditures could be assigned to different categories, e.g., some consumers might assign them to hedonic goods account while others to a utilitarian account. Moreover, consumers can manipulate their mental accounts in order to evade feelings of dissonance that appear when making an ancillary purchase in that category [53].

An understanding of how mental accounting might be used in the case of holiday decision-making is needed, particularly since earlier research mentions a "double-entry" mental accounting theory that explains the nature of mutual interactions between the pleasure of hedonic consumption and the pain of paying [54]. Holidays are largely a hedonic product and Prelec and Loewenstein [54] believe that these are enjoyed more when they are pre-paid since they feel "free".

Given the gaps in the literature presented above, this research had the following research objectives: (1) to examine the attitude-behaviour gap in relation to sustainable holidays decision-making; (2) to examine if and how neutralisation might be used by holidaymakers in their decision-making process; and (3) to explore if the concept of mental accounting is relevant to holiday decision-making.

The following section will briefly present the materials and methods used in the study. This is followed by an overview of the empirical results and the discussion of the key findings. 


\section{Materials and Methods}

\subsection{Methods}

Semi-structured interviews were considered the most appropriate methodology given the research objectives and the exploratory nature of this study, which aimed to uncover new insights into the holiday decision-making process. Interviews were also regarded as an effective method in eliminating group influences and social desirability bias related to views about aspects of ethical consumption [55]. The interviews were designed to be flexible in nature to allow for follow-up and probing questions based on the participants' responses, in order to uncover underlying issues regarding each individual's holiday decision-making [56].

\subsection{Sampling}

The interview cohort comprised 20 individuals, aged between 21 and 75 years old, with a balance across both genders (11 females and 9 males). The participants, both from a rural (village) and urban (small town) environment were used in the research. Social networks (i.e., extended family and friends) facilitated the approach of interviewees by informally advertising the research to potential participants. Those interested in taking part were then contacted via phone and arrangements for the interview were made. Given this was an exploratory piece of research, aiming to explore potential psychological decisional mechanisms, no particular consumer profile or segment was sought. However, the sample included interviewees who had some kind of travel history, given the researched topic. At the time of the interview, all the participants lived in Lower Saxony, which represents one of the north-western German federal state. Additionally, in order to obtain a wide range of perspectives regarding participants' holiday decision-making, the sample comprised individuals with different degrees of self-declared ethical and sustainability concerns and employment backgrounds (see Table 1). Despite the relative small sample, Crouch and McKenzie [57] (p. 483), argue that interview-based methodology is carried out with the view of obtaining insights beyond appearance and that even "a small number of cases (less than 20, say) will facilitate the researcher's close association with the respondents, and enhance the validity of fine-grained, in-depth inquiry in naturalistic settings." They go on to say that a project that examines "the dynamic qualities of a situation (rather than elucidating the proportionate relationships among its constituents), the issue of sample size — as well as representativeness - has little bearing on the project's basic logic".

Table 1. Summary of interviewees' demographic and ethical profile.

\begin{tabular}{cccc}
\hline $\begin{array}{c}\text { Participant } \\
\text { (Pseudonym) }\end{array}$ & Gender & Age & Occupation \\
\hline Maria & Female & 52 & Teacher and family business owner \\
Hildegard & Female & 75 & Pensioner \\
Jurgen & Male & 45 & Farm manager \\
Heidi & Female & 67 & Pensioner \\
Wolfgang & Male & 55 & Manager \\
Simon & Male & 23 & Junior agricultural manager \\
Miriam & Female & 37 & Kindergarten teacher \\
\hline
\end{tabular}


Table 1. Cont.

\begin{tabular}{cccc}
\hline $\begin{array}{c}\text { Participant } \\
\text { (Pseudonym) }\end{array}$ & Gender & Age & Occupation \\
\hline Hanna & Female & 21 & Undergraduate student \\
\hline Matthias & Male & 28 & Technician \\
Laura & Female & 25 & Postgraduate student \\
Christian & Male & 44 & Official inspector \\
Stefanie & Female & 45 & Management consultant \\
Florian & Male & 28 & Chemist \\
Annalena & Female & 29 & Pharmacist \\
Caroline & Female & 42 & Paralegal \\
Peter & Male & 57 & Technician \\
Silvia & Female & 48 & Cook \\
Bjorn & Male & 29 & Engineer \\
Maximilian & Male & 26 & Postgraduate student \\
Sophie & Female & 21 & Undergraduate student \\
\hline
\end{tabular}

\subsection{Interview Protocol and Data Analysis}

The interviews were conducted in the respondents' home and lasted between $30 \mathrm{~min}$ and one hour and $10 \mathrm{~min}$. The interview guide was translated from English into German by the one of the researchers and then translated back into English by a research assistant to confirm the accuracy of the translation. Additionally, a pre-test was carried with two individuals to determine the suitability of the interview design and content [58]. The interviews were conducted in German and audio recorded. They were subsequently translated and transcribed into English.

Thematic analysis was used in order to identify, analyse and report common patterns and themes within the transcribed data set $[59,60]$. The participants were assured of the anonymity of the interview and, thus, pseudonyms names are included in Table 1 . The provision of anonymity complied with ethics procedures but also encouraged interviewees to express their ideas, thoughts and feelings [12] and thus minimised the social desirability bias, which is anticipated when participants' identities and beliefs are exposed [61]. Each individual gave consent for taking part in this project.

\section{Results}

Several themes, related to ethical behaviours and sustainable holidays, have emerged from the interview data and these are detailed below.

\subsection{Sustainable Holidays and Motivations}

The interviews revealed that the German tourists in the cohort like to be "in nature" during their holidays. They go cycling, hiking or swimming and the majority of them go on beach and adventure holidays.

When asked about the meaning of sustainable holidays, the participants perceived it to be an environmentally friendly holiday within their own country of residence. Holidays abroad were not regarded as ecologically responsible since consumers believe that airplanes display the most 
environmentally harmful means of transport with high $\mathrm{CO}_{2}$ emissions. Sustainable holidays were further considered to be less luxurious and numerous participants thought of camping holidays and bicycle trips as a sustainable holiday. The majority of the interviewed German holidaymakers declared being aware of sustainable holidays. Particularly, individuals aged 18-26 and 38-49 years old were highly aware of this form of holiday, but individuals over the age of 50 years old were less aware.

Overall, the majority of the participants confessed not having been on a sustainable holiday in the past. The findings of the present study revealed that a large number of participants declared they would select the sustainable holiday product instead of the regular alternative, if money were not a concern.

"I would book the sustainable holiday...well it is the same as purchasing organic products, so I do know that this is the right decision...I would feel guilty when behaving unethically." (Maximilian)

The participant reported both positive and negative emotions as motivations for choosing a sustainable holiday choices. They would feel happy and proud, as they would contribute to the conservation of the environment as well as the holiday destination.

"Proud...yes, I would be proud ... you know that you did something good for the environment. But it is always a matter of costs..." (Wolfgang)

Negative emotions such as feeling "bad", irresponsible and guilty seem to deter some holidaymakers from choosing unsustainable holidays or lead them to offset their negative outcomes:

"I pay for the carbon offset to feel less guilty about flying to the holiday destination." (Christian)

Overall, even though the interviewed Germans claimed to have a largely sustainable lifestyle, they regarded ethics and sustainability considerations as secondary in their holiday decision-making process. This was mainly due to the hedonic value of the holiday; its price-performance ratio and convenience, which remained the decisive criteria for holiday purchase decisions.

\subsection{Unethical Choices and Neutralisation}

When asked about the role of ethical considerations in their daily consumptions choices, most participants were keen to offer explanations for why these are not considered. The interviewees justified unethical decisions in the light of weighing the costs and benefits (i.e., the "economic rationalist" neutralisation strategy). Others have used the "denial of responsibility" neutralisation technique by arguing that they had no other choice but to buy certain products.

"No, I don't take ethical considerations into account when purchasing products...price and quality are more important to me." (Caroline)

More importantly, new justification strategies were found such as "perceived limited impact" and “scepticism" toward companies' green activities:

"Yes sure...you think about the airplanes that need a lot of kerosene... but I believe since we don't go on holiday very often and it was the last time that we went by plane...I would think this is okay." (Maria) 
"I do feel good and I don't feel guilty about not choosing the sustainable holiday alternative because sustainability doesn't always mean that a product or service is sustainable. That's the problem." (Peter)

\subsection{Mental Accounting}

Regarding Thaler's [52] theory of mental accounting, the findings of the present study showed that the interviewed German consumers undertake mental accounting when purchasing products and services. They possess different accounts for hedonic and utilitarian goods as well as for windfall gains and their monthly salary. Some interesting findings were revealed in terms of consumers' age and how it influences the allocation of a work-related bonus. The data showed that individuals aged between 38 and 49 years old seem to consider the bonus as "pocket money" and would spend it on hedonic goods, whereas those over the age of 50 years would see the bonus as part of their monthly salary and would use it for utilitarian consumption choices.

In terms of payment methods, it was revealed that consumers either felt that the holiday was free or they thought about the money paid in advance to engage in mental budget planning as described by Heath and Soll [53]. Most of the interviewees confessed tracking their expenses in order not to overspend on their set budget (i.e., displaying self-control efforts) and estimated that they were under-spending more than overspending.

\subsection{Compensation of Behaviours}

Related to mental accounting, another theme that emerged from the interviews was related to the indication of consumers having two mental accounts for "ethical" and "unethical" behaviours, which allowed for compensation between different types of behaviours. The interviewees appeared to compensate their less sustainable holiday decisions with ethical and/or sustainable behaviour outside the holiday timeframe. More specifically, they pointed out towards saving mental credits when engaging in ethically responsible behaviour such as the purchase of organic and fair trade products, the conscious usage of resources (water, electricity, heating oil) and ecologically friendly means of transport. These ethical mental credits would then balance less sustainable and ethical holiday-related decisions such as flying to their holiday destination or booking the mainstream holiday option.

"My everyday life carbon footprint is low. I don't have a car...I always go by bike...I try to save energy...I always put a lot in the washing machine...I don't have long showers. Well...after the flight, I do feel less guilty since I usually go everywhere by bike so I don't produce $\mathrm{CO}_{2}$ emissions and harm the environment. Then I should be allowed to fly once a year." (Laura)

In addition, participants considered holidays as independent from their individual ecological behaviour in the domestic context and they believed that everyday life decisions are more important than their behaviour during the holiday. Some interviewees were aware of the carbon offset option for travelling and holidays but they have argued against buying by claiming they would able to save more energy at home in a year to counteract it. 
The findings revealed that when using this form of mental accounting (i.e., compensation between ethical and unethical accounts), consumers did not experience cognitive dissonance.

\section{Discussion}

In this section, the main findings will be discussed in the light of the extant literature and practical implications related to these findings are put forward. The research limitations will also be discussed and directions for future research will be outlined.

\subsection{Discussion of Findings}

The data showed that interviewees' preferences were consistent with research by Mehmetoglu [37], who argued that Germans are particularly interested in authentic and nature-based holiday choices. However his assumption that, because of these interests, German tourists might become sustainable tourists is not supported by the present study's findings. The interviewees regarded holidays as a hedonic product, which might explain their lack of consideration for sustainable characteristics and alternative holiday options. These findings are aligned with Duman and Matilla's [62] view on the hedonic value of holidays. Furthermore, the findings are similar with Budeanu's [34] and Böhler et al. 's [6] view that tourists are less interested in engaging in ethical purchase behaviour in a tourism context. The German holidaymakers, who took part in the present study, considered holidays as independent from their everyday life decisions, which they felt are more important in terms of ethical commitment. This confirms the findings of other recent studies such as that of Barr et al. [43].

Given the interviewees' misconceptions about some of the characteristics of sustainable holidays, tourism organisations and operators should ensure that this is addressed via marketing communications. Consumers of tourism products should be made aware of the different types of holidays available (domestic, abroad, nature-based, luxurious) and their various degrees of sustainability.

In relation to neutralisation, the participants have justified their choice of unsustainable tourism products via the standard neutralisation techniques $[47,49,50]$ but new justification strategies such as "perceived limited impact" and "scepticism" toward companies' green activities were found. These findings point out the need for further research in the specific context of holidays and other tourism products, which might uncover more context-specific neutralisation techniques.

The findings related to generic mental accounting were partly consistent with research by Prelec and Loewenstein [54] who argued that pre-paid holidays are enjoyed as they were free and negative thoughts were softened by the assurance that consumers will get a counter value for their payment. However, it appeared that middle-aged consumers (38-49 years) are more likely to spend windfall gains like a bonus on hedonic products compared to older consumers, who would be more likely to make utilitarian decisions. Given that holidays are perceived as hedonic goods, this has implications for how holidays are portrayed in marketing communications for these different ages groups. Moreover, the marketing of sustainable holidays could be more successful is they are portrayed as being "no less hedonic" than regular holiday. Additionally, the potential higher price of some sustainable holidays could be justified to consumers by an enhanced hedonic experience and uniqueness, according to the type of holiday.

A contribution and an interesting finding of this study is related the discovery that individuals, in currently researched context, appear to have a mental account for "ethical" behaviours and one for 
"unethical" behaviours. Particularly, the accumulation of mental credits from ethical choices enables them to compensate for unethical behaviours. This mental process allows consumers to opt for unsustainable holidays and guards them from experiencing anticipated negative emotions or cognitive dissonance. This compensation between "ethical" and "unethical" mental accounts can explain the lack of spillover effects between ethical and sustainable behaviours at home and holiday-related choices/behaviours.

This key finding should be considered when designing efficient marketing communications to promote sustainable holidays. To counteract this internal balancing of mental accounts, advertising could show factual information and figures about the consequences and carbon footprint of unsustainable holiday-related choices. Following this, the equivalent of sustainable behaviours at home should be presented to show the difficulty of actually offsetting these choices in the home context and with day-to-day behaviours. For example, train versus plane versus ferry versus car emissions could be shown followed by the equivalent of energy savings in one's home that would counteract for each of these environmental footprints.

Additionally, marketing communications could incorporate positive or negative emotions (according to the communications scenario) to encourage consideration of sustainable holidays among consumers with various levels of ethical and sustainability concerns. These should link the purchase of sustainable holidays with emotional rewards such as satisfaction, happiness, pleasure and pride, which would increase one's self-esteem. Alternatively, marketing campaigns could portray the negative environmental consequences of unsustainable holiday-related choices. These could generate negative anticipated emotions (regret, guilt, shame) and could influence consumers' choices, as they would aim to induce cognitive dissonance. Careful consideration based on further research and pre-testing might best advise on the most suitable approach regarding the use of emotions in marketing communications.

\subsection{Limitations and Future Research Directions}

Despite the study's theoretical contribution to the existent body of knowledge and its implications for practitioners, several limitations should be acknowledged. The present study is exploratory in nature and has, thus, employed a small cohort of interviewees. A larger sample is required to confirm these findings among German and other holidaymakers. A bigger cohort will also ensure validation of this initial exploratory study. Nonetheless, the present research could be seen as a building block for future projects examining consumers' decision-making process and barriers to sustainable behaviour, whether this is related to holidays or other products.

While the chosen respondents were deemed suitable given the Germans' preference for nature and adventure holidays as well as their high levels of concern in some areas of ethical and sustainable consumption (including sustainable holidays), future studies should test these findings in other European countries and across cultures. We recommend future research pursue further the findings regarding the lack of spillover. For example, using alternative theories (e.g., Activity Theory [63]) and methodology, future research could identify in relation to which practices or dimensions of the holidays, spillovers are more likely to happen e.g., use of energy, water, travelling choice, littering or recycling behaviour at the holiday destination, etc. 
Another limitation is related to the difficulty of individuals to acknowledge and express mental processes, which in some situations might occur unconsciously. Additionally, as a cross-sectional study, the present research relied on recent experiences that consumers can recall and detail. Longitudinal studies in qualitative form (e.g., diaries) and quantitative form (e.g., experiments and survey) could be used in conjunction to explore better these complex decision-making processes. These would add to the extension and validation of the present findings.

\section{Author Contributions}

Both authors contributed to writing this paper. Larissa Schütte also collected, transcribed and analysed the data. Diana Gregory-Smith contributed to the research design, data analysis, and the writing and revising of the paper.

\section{Conflicts of Interest}

The authors declare no conflict of interest.

\section{References}

1. Auger, P.; Devinney, T.M. Do what consumers say matter? The misalignment of preferences with unconstrained ethical intentions. J. Bus. Ethics 2007, 76, 361-383.

2. Bray, J.; Johns, N.; Kilburn, D. An exploratory study into the factors impeding ethical consumption. J. Bus. Ethics 2010, 89, 597-608.

3. Carrigan, M.; Attalla, A. The myth of the ethical consumer-Do ethics matter in purchase behaviour? J. Consum. Mark. 2001, 18, 560-577.

4. Carrington, M.J.; Neville, B.A.; Whitwell, G.J. Why ethical consumers don't walk their talk: Towards a framework for understanding the gap between the ethical purchase intentions and actual buying behaviour of ethically minded consumers. J. Bus. Ethics 2010, 97, 139-158.

5. Follows, S.B.; Jobber, D. Environmentally responsible purchase behaviour: A test of a consumer model. Eur. J. Mark. 2000, 34, 723-746.

6. Böhler, S.; Grischkat, S.; Haustein, S.; Hunecke, M. Encouraging environmentally sustainable holiday travel. Transp. Res. A Policy Pract. 2006, 40, 652-670.

7. Diekmann, A.; Preisendorfer, P. Green and greenback: The behavioral effects of environmental attitudes in low-cost and high-cost situations. Ration. Soc. 2006, 15, 441-472.

8. Hibbert, J.F.; Dickinson, J.E.; Gössling, S.; Curtin, S. Identity and tourism mobility: An exploration of the attitude-behaviour gap. J. Sustain. Tour. 2013, 21, 999-1016.

9. Andorfer, V.A.; Liebe, U. Research on fair trade consumption-A review. J. Bus. Ethics 2012, 106, 415-435.

10. Aertsens, J.; Mondelaers, K.; Verbeke, W.; Buysse, J.; Van Huylenbroeck, G. The influence of subjective and objective knowledge on attitude, motivations and consumption of organic food. Br. Food J. 2011, 113, 1353-1378. 
11. Paharia, N.; Vohs, K.D.; Deshpandé, R. Sweatshop labor is wrong unless the shoes are cute: Cognition can both help and hurt moral motivated reasoning. Organ. Behav. Hum. Decis. Process. 2013, 121, 81-88.

12. Freestone, O.M.; McGoldrick, P.J. Motivations of the ethical consumer. J. Bus. Ethics 2008, 79, 445-467.

13. Starr, M.A. The social economics of ethical consumption: Theoretical considerations and empirical evidence. J. Socio-Econ. 2009, 38, 916-925.

14. Low, W.; Davenport, E. To boldly go Exploring ethical spaces to re-politicise ethical consumption and fair trade. J. Consum. Behav. 2007, 6, 336-348.

15. Nicholls, A.; Lee, N. Purchase decision-making in fair trade and the ethical purchase 'gap': Is there a fair trade 'twix'? J. Strateg. Mark. 2006, 14, 369-386.

16. Kim, Y.K.; Forney, J.; Arnold, E. Environmental messages in fashion advertisements: Impact on consumer responses. Cloth. Text. Res. J. 1997, 15, 147-154.

17. Futerra, S.C.L. The Rules of the Game: The Principles of Climate Change Communication; Department for Environment, Food and Rural Affairs: London, UK, 2005.

18. Shaw, D.; Shiu, E. The role of ethical obligation and self-identity in ethical consumer choice. Int. J. Consum. Stud. 2002, 26, 109-116.

19. Anckar, B.; Walden, P. Self-booking of high-and low-complexity travel products: Exploratory findings. Inf. Technol. Tour. 2001, 4, 151-165.

20. Belk, R.; Devinney, T.M.; Eckhardt, G. Consumer ethics across cultures. Consum. Mark. Cult. 2005, 8, 275-289.

21. Macbeth, J. Towards an ethics platform for tourism. Ann. Tour. Res. 2005, 32, 962-984.

22. Butcher, J. The Moralisation of Tourism: Sun, Sand... and Saving the World? Routledge: London, UK, 2005.

23. Baptista, J.A. The virtuous tourist: Consumption, development, and nongovernmental governance in a Mozambican village. Am. Anthropol. 2012, 114, 639-651.

24. Holden, A. In need of new environmental ethics for tourism? Ann. Tour. Res. 2003, 30, 94-108.

25. Euromonitor International. Passport-Travel and Sustainability: Striking the Right Balance. Available online: http://www.euromonitor.com/travel-and-sustainability-striking-the-right-balance/ report (accessed on 8 September 2012).

26. Lovelock, B. Ethical travel decisions travel agents and human rights. Ann. Tour. Res. 2008, 35, 338-358.

27. Peeters, P.; Landre, M. The emerging global tourism geography-An environmental sustainability perspective. Sustainability 2011, 4, 42-71.

28. Scott, D.; Gössling, S.; Hall, C.M. Tourism and Climate Change: Impacts, Adaptation and Mitigation; Routledge: Abingdon, UK, 2012.

29. Scott, D.; Amelung, B.; Becken, S.; Ceron, J.; Dubois, G.; Gössling, S.; Simpson, M. Climate Change and Tourism: Responding to Global Challenges; Technical Report; UNWTO \& UNEP: Madrid, Spain, 2008; pp. 23-250.

30. Barr, S.; Prillwitz, J. Green travellers? Exploring the spatial context of sustainable mobility styles. Appl. Geogr. 2012, 32, 798-809. 
31. Shaw, S.; Thomas, C. Discussion note: Social and cultural dimensions of air travel demand: Hyper-mobility in the UK? J. Sustain. Tour. 2006, 14, 209-215.

32. Dellaert, B.G.; Ettema, D.F.; Lindh, C. Multi-faceted tourist travel decisions: A constraint-based conceptual framework to describe tourists' sequential choices of travel components. Tour. Manag. 1998, 19, 313-320.

33. Font, X.; Harris, C. Rethinking standards from green to sustainable. Ann. Tour. Res. 2004, 31, 986-1007.

34. Budeanu, A. Sustainable tourist behaviour-A discussion of opportunities for change. Int. J. Consum. Stud. 2007, 31, 499-508.

35. McKercher, B.; Prideaux, B.; Cheung, C.; Law, R. Achieving voluntary reductions in the carbon footprint of tourism and climate change. J. Sustain. Tour. 2010, 18, 297-318.

36. Barr, S.; Shaw, G.; Gilg, A.W. The policy and practice of 'sustainable lifestyles'. J. Environ. Plan. Manag. 2011, 54, 1331-1350.

37. Hall, C.M. Framing behavioural approaches to understanding and governing sustainable tourism consumption: Beyond neoliberalism, "nudging" and "green growth"? J. Sustain. Tour. 2013, 21, 1091-1109.

38. De Young, R. New ways to promote proenvironmental behavior: Expanding and evaluating motives for environmentally responsible behavior. J. Soc. Issues 2000, 56, 509-526.

39. Barr, S.; Gilg, A. Sustainable lifestyles: Framing environmental action in and around the home. Geoforum 2006, 37, 906-920.

40. Thørgersen, J.; Ölander, F. Spillover of environment-friendly consumer behaviour. J. Environ. Psychol. 2003, 23, 225-236.

41. Thørgersen, J. A cognitive dissonance interpretation of consistencies and inconsistencies in environmentally responsible behavior. J. Environ. Psychol. 2004, 24, 93-103.

42. Haq, G.; Whitelegg, J.; Conderby, S.; Owen, A. The use of personalised social marketing to foster voluntary behavioural changes for sustainable travel and lifestyles. Local Environ. 2008, 13, 549-569.

43. Barr, S.; Shaw, G.; Coles, T.; Prillwitz, J. 'A holiday is a holiday': Practicing sustainability, home and away. J. Transp. Geogr. 2010, 18, 474-481.

44. Baker, S.; Thompson, K.E.; Engelken, J.; Huntley, K. Mapping the values driving organic food choice: Germany vs the UK. Eur. J. Mark. 2004, 38, 995-1012.

45. Mehmetoglu, M. Predictors of sustainable consumption in a tourism context: A CHAID approach. Adv. Hosp. Leis. 2009, 5, 3-23.

46. Anable, J.; Gatersleben, B. All work and no play? The role of instrumental and affective factors in work and leisure journeys by different travel modes. Transp. Res. A Policy Pract. 2005, 39, 163-181.

47. D'Astous, A.; Legendre, A. Understanding consumers' ethical justifications: A scale for appraising consumers' reasons for not behaving ethically. J. Bus. Ethics 2009, 87, 255-268.

48. Mitchell, V.W.; Chan, K.L.J. Investigating UK consumers' unethical attitudes and behaviour. J. Mark. Manag. 2002, 18, 5-26.

49. Chatzidakis, A.; Hibbert, S.; Smith, A. "Ethically concerned, yet unethically behaved": Towards an updated understanding of consumer's (un)ethical decision making. Adv. Consum. Res. 2006, 33, 693-698. 
50. McGregor, S.L.T. Conceptualizing immoral and unethical consumption using neutralization theory. Fam. Consum. Sci. Res. J. 2008, 36, 261-276.

51. Tversky, A.; Kahneman, D. The framing of decisions and the psychology of choice. Science 1981, $211,453-458$.

52. Thaler, R. Mental accounting and consumer choice. Mark. Sci. 1985, 4, 199-214.

53. Heath, C.; Soll, J.B. Mental budgeting and consumer decisions. J. Consum. Res. 1996, 23, 40-52.

54. Prelec, D.; Loewenstein, G. The red and the black: Mental accounting of savings and debt. Mark. Sci. 1998, 17, 4-28.

55. Vermeir, I.; Verbeke, W. Sustainable food consumption: Exploring the consumer "attitude-behavioral intention" gap. J. Agric. Environ. Ethics 2006, 19, 169-194.

56. Malhotra, N.K. Marketing Research: An Applied Orientation, 6th ed.; Pearson Education Inc.: New York, NY, USA, 2010.

57. Crouch, M.; McKenzie, H. The logic of small samples in interview-based qualitative research. Soc. Sci. Inf. 2006, 45, 483-499.

58. Turner, D.W. Qualitative Interview Design: A Practical Guide for Novice Investigators. Qual. Rep. 2010, 15, 754-760.

59. Braun, V.; Clarke, V. Using thematic analysis in psychology. Qual. Res. Psychol. 2006, 3, 77-101.

60. Thompson, C.J. Interpreting consumers: A hermeneutical framework for deriving marketing insights from the texts of consumers' consumption stories. J. Mark. Res. 1997, 34, 438-456.

61. Fernandes, M.F.; Randall, D.M. The Nature of Social Desirability Response Effects in Ethics Research. Bus. Ethics Q. 1992, 2, 183-205.

62. Duman, T.; Mattila, A.S. The role of affective factors on perceived cruise vacation value. Tour. Manag. 2005, 26, 311-323.

63. Engeström, Y.; Miettinen, R.; Punamäki, R.L. Perspectives on Activity Theory; Cambridge University Press: Cambridge, UK, 1999.

(C) 2015 by the authors; licensee MDPI, Basel, Switzerland. This article is an open access article distributed under the terms and conditions of the Creative Commons Attribution license (http://creativecommons.org/licenses/by/4.0/). 